\title{
Química de elementos-traço nos sedimentos do Lago do Parú (Manacapuru - Amazonas), sob influência do pulso de inundação do baixo Rio Solimões
}

\author{
Adriana KOUMROUYAN ${ }^{1}$, Genilson Pereira SANTANA² \\ RESUMO \\ O objetivo deste estudo foi determinar as concentraçōes totais e em frações geoquímicas de $\mathrm{Fe}, \mathrm{Mn}$, Co, Cu e Zn em sedimentos, \\ coletados nos períodos de seca (2005) e cheia (2006) do Lago do Parú. Nas partículas de sedimento seco ao ar (SSA) < 45 \\ $\mu \mathrm{m}$ foi feita uma extração seqüencial pelo método de Tessier et al. (1979) que separa os elementos nas frações geoquímicas \\ trocável, carbonácea, oxídica, orgânica e residual. As amostras de extrato diluídas foram lidas em cada fração, por espectrometria \\ de absorção atômica de chama, sendo que o Fe apresentou a maior concentração total e uma forte associação com óxidos. O \\ Mn alcançou a maior fração trocável dentre os elementos, em ambas as estaçōes analisadas. O Zn obteve uma fração trocável \\ constante entre os dois períodos analisados. $\mathrm{O} \mathrm{Cu}$ se caracterizou por apresentar forte ligação pela fração orgânica, não variando \\ de uma estação para outra nesta fração. $\mathrm{O}$ Co apresentou comportamento similar ao do $\mathrm{Cu}$, exceto pela fração orgânica que \\ apresentou diferença de concentração entre os períodos, sendo maior na cheia. As análises multivariadas confirmaram que os \\ metais foram movimentados entre as frações geoquímicas do período seco para o de cheia.
}

PALAVRAS-CHAVE: Metais-traço, Extração seqüencial, Lago de planície inundável, Lago de várzea, Amazônia central.

\section{Trace elements chemical in Lago do Parú (Manacapuru - Amazonas) sediments, under Lower Solimões River flood pulse influence}

\begin{abstract}
The aim of this work was to determine whole and geochemical fractions of $\mathrm{Fe}, \mathrm{Mn}, \mathrm{Co}, \mathrm{Cu}$ and $\mathrm{Zn}$ concentrations from sediments collected at low (2005) and high (2006) water seasons in Lago do Parú. From $<45 \mu \mathrm{m}$ air dried sediment particles was made a Tessier et al. (1979) method to sequential extraction, which separates elements in exchangeable, bound to carbonates, bound to iron and manganese oxides, bound to organic matter and residual geochemical fractions. Diluted samples were read in each fraction, by flame atomic absorption spectrometry, where Fe showed the highest whole concentration and strong association with oxides. Mn reached the biggest exchangeable fraction among elements in both analyzed periods. Cu showed strong association by organic fraction and don't presented difference of concentration between periods. Co presented similar behavior of $\mathrm{Cu}$, except for organic fraction, in which showed difference between periods, where was bigger in high water level period. Multivariate statistical analyses confirmed that metals were displaced in sediments geochemical fractions at low and high water seasons.
\end{abstract}

KEYWORDS: Trace metals, Sequential extraction, Floodplain Lake, várzea lake, Central Amazonia.

1 Universidade Federal do Amazonas. Centro de Ciências do Ambiente. Av. Gal. Rodrigo Octávio Jordão Ramos, 3.000, Coroado II - Manaus - AM - 69077-000. e-mail: nanakoya@click21.com.br

${ }^{2}$ Universidade Federal do Amazonas. Departamento de Química. Av. Gal. Rodrigo Octávio Jordão Ramos, 3.000, Coroado II - Manaus - AM - 69077-000. e-mail: gsantana@ufam.edu.br 


\section{INTRODUÇÃO}

A extração química seqüencial foi originalmente desenvolvida para prover informaçōes sobre elementos potencialmente tóxicos na qualidade da água. Recentemente, métodos de extração química seletiva têm sido utilizados em estudos ecotoxicológicos, em comparações entre "antes e depois" de possíveis impactos (Bacon \& Davidson, 2008) e na verificação de mudanças sazonais (Pestana \& Formoso, 2003) sobre o comportamento de metais pesados. Tais métodos foram desenvolvidos devido à especiação que os metais normalmente sofrem em matrizes sólidas (Hlavay et al., 2004), isto é, se associam às diferentes frações geoquímicas dos solos e sedimentos de acordo com as condições físico-químicas do ambiente (Syrovetnik, 2005).

O termo especiação química é definido por Ure (1991) como 'o processo ativo de identificação e quantificação das diferentes formas ou fases de espécies definidas na qual um elemento ocorre em um material ou a descrição das quantidades e tipos de espécies, formas ou fases presentes no material. Ele ainda propôs dividir a especiação em três classes:

(a) Especiação clássica, referindo-se a compostos químicos específicos ou ao estado de oxidação dos elementos;

(b) Especiação funcional, que se refere ao papel observado ou o comportamento do elemento (exemplos: espécies móveis ou disponíveis às plantas); e

(c) Especiação operacional, referindo-se à situação onde o reagente usado para extrair a amostra define a espécie, sendo a extração química seqüencial um exemplo deste tipo de especiação.

Os passos dos métodos de extração seqüencial tentam imitar mudanças nas condições ambientais como acidificação, redução e oxidação (Bacon \& Davidson, 2008), processos muito recorrentes nos lagos de várzea amazônicos, como a entrada de água ácida pelas cabeceiras de água preta presentes nestes corpos de água (acidificação) e o acúmulo de sedimentos anóxicos no fundo dos mesmos (Tundisi et al., 1984). Em tais métodos, as frações são extraídas das amostras com soluçōes de polaridade crescente, sendo as primeiras frações obtidas consideradas as mais biodisponíveis (Bacon \& Davidson, 2008).

O grande problema quanto aos métodos de extração seqüencial é a falta de uma padronização dos mesmos, impossibilitando comparações entre diferentes trabalhos. Dentre os métodos de extração seqüencial, os mais utilizados são os da Comunidade de Referência de Bureau (BCR), original e revisado, e o desenvolvido por Tessier et al. (1979). O método de Tessier é o procedimento mais largamente utilizado em extração seqüencial (Syrovetnik, 2005), sendo considerado adequado para o propósito deste trabalho. A única alteração ao mesmo foi feita em relação à temperatura de secagem das amostras. Sendo assim, a seletividade assumida para as cinco frações de partição dos metais foi: (1) Trocável / deslocada com sal, (2) Carbonácea / extraída com ácido / sorvida, (3) Oxídica / redutível / ligada a óxidos e hidróxidos de ferro e manganês, (4) Orgânica / oxidável / ligada à matéria orgânica e (5) Residual / silicato.

$\mathrm{Na}$ Amazônia, o primeiro estudo publicado sobre partição de metais-traço em sedimentos foi realizado por Nascimento \& Fenzl (1997) em amostras do Rio Guamá, que banha o sul da cidade de Belém (estado do Pará), sendo este provavelmente impactado por banhar uma capital. Já o Lago do Parú, objeto deste estudo, é um lago considerado natural, ou seja, não-impactado por ações antrópicas de grande porte. Sendo assim, este estudo é apenas o começo de uma série de outros trabalhos que possam vir a contribuir para o conhecimento e posterior estabelecimento de padrões dos elementos-traço nos sedimentos de lagos de várzea do Rio Solimões.

O objetivo deste estudo foi quantificar as concentrações totais, bem como as partições geoquímicas percentuais, dos elementos $\mathrm{Fe}, \mathrm{Mn}, \mathrm{Co}$, Cu e $\mathrm{Zn}$ nos sedimentos do Lago do Parú em um período de seca (2005) e um de cheia (2006) no baixo Solimôes, com a finalidade de tornar conhecida a influência desses períodos na dinâmica dos metais contidos nos sedimentos de um lago de várzea.

\section{MATERIAL E MÉTODOS}

\section{ÁREA DE ESTUDO}

O município de Manacapuru situa-se próximo à confluência dos Rios Negro e Solimôes, a 68 km de Manaus em linha reta e a $88 \mathrm{~km}$ por via fluvial, abrangendo uma área de $7.329 \mathrm{~km}^{2}$ (IBGE, 2007). O Lago do Parú (60 32' W; $3^{\circ} 17^{\prime}$ S) situa-se à margem esquerda do Baixo Solimões e compreende uma área de aproximadamente $18 \mathrm{~km}^{2}$, encontrando-se a $20 \mathrm{~km}$ da sede do município de Manacapuru (Figura 1).

Quanto à geomorfologia, o Lago do Parú é um lago dendrítico, como o Lago Calado, seu vizinho $\left(60^{\circ} 35^{\prime} \mathrm{W}\right.$, $3^{\circ} 16^{\prime}$ S) (Behling et al., 2001), localizado numa área de interflúvios tabulares, com relevo de topo aplainado, separados por vales de fundo em "v" (Radambrasil, 1978). O Lago do Parú encontra-se inserido numa pequena área de Plintossolos Háplicos, cercada por Latossolos Amarelos (IBGE, 2007). A classificação climática de Köppen é do tipo Amw’, designativo de clima tropical chuvoso com uma estação seca de pequena duração. A precipitação total anual é próxima a $2.250 \mathrm{~mm}$ (Radambrasil, 1978). 


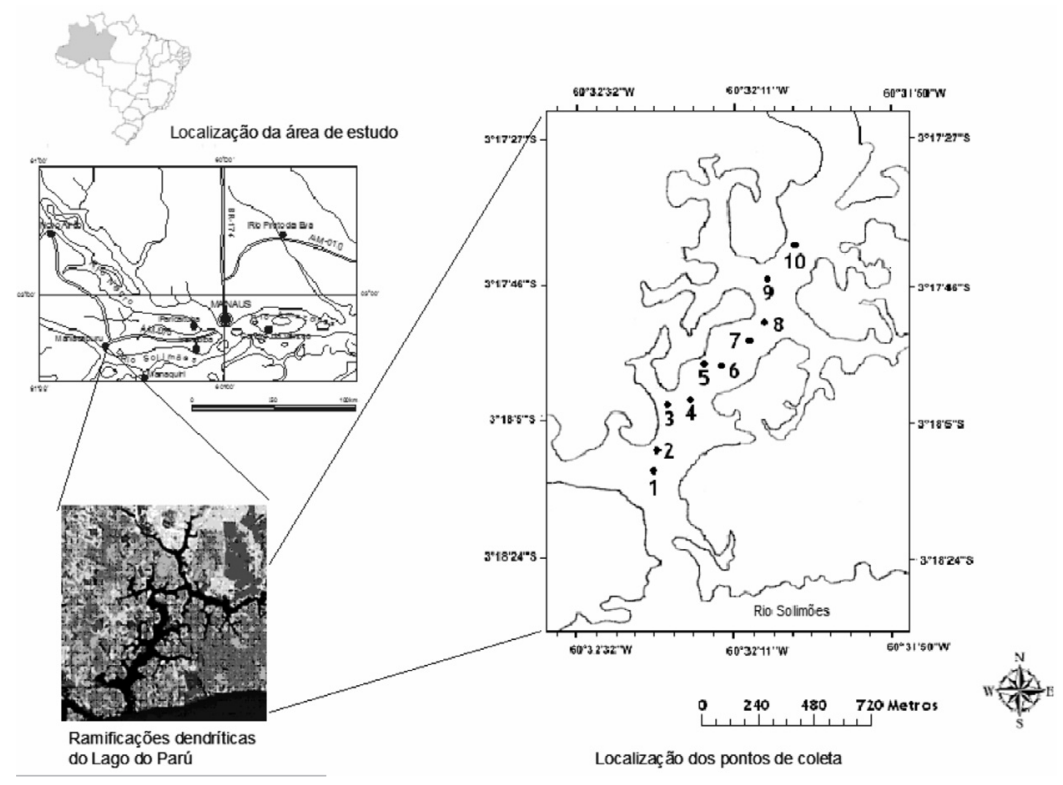

de ar no ambiente para que as partículas atmosféricas não carreassem os elementostraço em excesso. Depois de secas, todas as amostras passaram por um processo de desagregação ou destorroamento, com auxílio de almofariz e pistilo, e posteriormente foram peneiradas a seco em malhas Granutest de $53 \mu \mathrm{m}$ (ou 270 mesh), com o auxílio de um agitador mecânico Produtest, sendo então homogeneizadas. As malhas das peneiras foram limpas e esterilizadas entre uma amostra e outra, para que não houvesse contaminação, primeiramente, a seco, com uma escova dental de cerdas duras e, depois, foram retiradas as partículas mais finas do sedimento, no aparelho de ultrassom UltraSonic Cleaner, marca Thorton, modelo USC 5000, por 10 minutos. Feito isto, as malhas receberam um banho de água corrente de torneira e seguidas rinsadas de água deionizada, sendo então secas na estufa a uma temperatura de $60^{\circ} \mathrm{C}$ e em 20 minutos estavam secas para reutilização, depois de frias, na amostra seguinte.

Antes da pesagem para cada procedimento, as amostras de SSA foram secas por dois dias em estufa a $40{ }^{\circ} \mathrm{C}$, visando a garantia da integridade das propriedades físico-químicas dos metais estudados (Kahn \& Soltanpour, 1978). Todas as amostras de sedimento utilizadas nas análises físicas e químicas deste trabalho foram assim normalizadas.

\section{EXTRAÇÃO}

Os primeiros quatro passos do método de Tessier et al. (1979) foram seguidos para a extração fracionada ou seletiva dos metais nas formas trocável (F1), carbonácea (F2), oxídica (F3) e orgânica (F4). A extração total das amostras de sedimentos foi realizada através de digestão ácida com uma mistura 5:1 de ácidos fluorídrico e perclórico (HF$\mathrm{HClO}_{4}$ ), descrita também por Tessier et al. (1979), e da qual foram subtraídos a soma $\mathrm{F} 1+\mathrm{F} 2+\mathrm{F} 3+\mathrm{F} 4$ para a obtenção dos resultados da fração residual (F5). O método de Tessier $e t$ al. (1979) detalhado encontra-se na Figura 2 e as soluçôes utilizadas para tal constam na Tabela 1 .

Todas as amostras foram extraídas em triplicatas, em tubos de centrífuga de polietileno de $50 \mathrm{~mL}$, para a realização da extração seletiva, e em cadinhos de Teflon, para a extração total. Os extratos obtidos foram diluídos em 20 vezes para as leituras de Co, Cu e Zn e em 50 vezes para as leituras de Fe e $\mathrm{Mn}$. As diluições foram feitas com água deionizada, garantindo a ausência de metais pesados nas amostras, e acidificadas em $\mathrm{HNO}_{3}$. Todos os materiais utilizados durante o procedimento para análises químicas foram esterilizados em banho de $\mathrm{HNO}_{3}$ a $10 \%$ e receberam três rinsadas de água deionizada. 


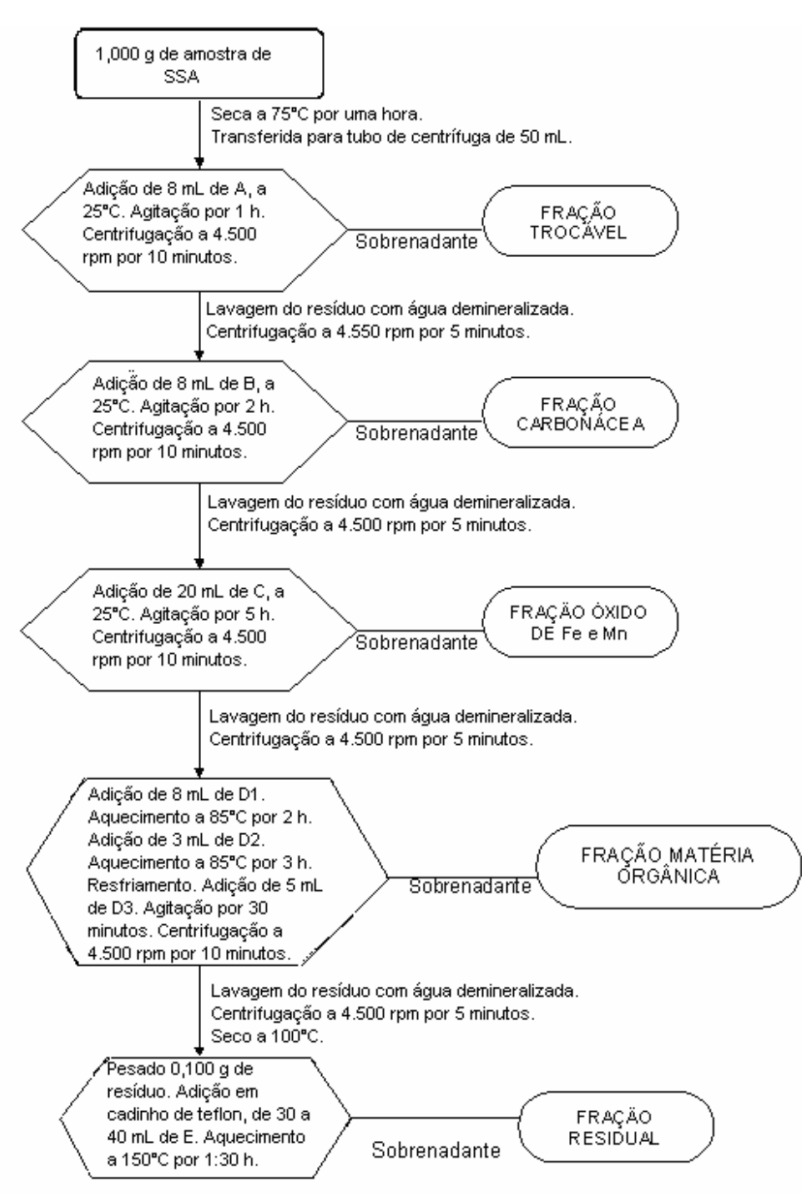

Figura 2 - Método de extração seqüencial proposto por Tessier et al. (1979).

\section{ANÁLISES FÍSICAS E QUIIMICAS}

\section{DIFRAÇÃO DE RAIOS X}

Pequenas parcelas iguais de cada amostra de SSA total, de granulação $<53 \mu \mathrm{m}$, do período de seca, foram colocadas em cadinho de porcelana para homogeneização. Feito isto, a amostra foi cuidadosamente colocada em placa metálica, para leitura no difratômetro de raios X marca Shimadzu. O mesmo procedimento foi adotado para as amostras de sedimento do período de cheia. A medida foi realizada usando uma radiação $\mathrm{KaCu}$, com constante de tempo de 5 segundos, nos ângulos de 3 a $60^{\circ} 2 \theta$.

\section{ESPECTROMETRIA DE ABSORÇÃO ATÔMICA}

Em cada amostra foram determinadas as concentrações de $\mathrm{Fe}, \mathrm{Mn}, \mathrm{Co}, \mathrm{Cu}$ e $\mathrm{Zn}$ por espectrometria de absorção atômica (GBC, AAS 932), utilizando-se o método direto, chama de ar-acetileno e reagente padrão certificados (SpecSol) cujo valor da solução é de $1.000 \pm 0,003 \mathrm{mg} \mathrm{g}^{-1}$. Chama e comprimentos de onda foram regulados para cada elemento de acordo com o
Tabela 1 - Soluções utilizadas para fazer a extração seqüencial de metais pesados nas amostras de sedimento, para extração pelo método de Tessier et al. (1979).

\begin{tabular}{|c|c|c|c|}
\hline $\begin{array}{l}\text { Fração } \\
\text { Geoquímica }\end{array}$ & Soluções extratoras & $\mathrm{pH}$ & Legenda \\
\hline Trocável & $\mathrm{MgCl}_{2}$ a $1,00 \mathrm{~mol} \mathrm{~L}^{-1}$ & 7,0 & A \\
\hline Carbonácea & $\mathrm{NaOAc}$ a $1,00 \mathrm{~mol} \mathrm{~L}^{-1}$ & 5,0 & B \\
\hline Oxídica & $\begin{array}{l}\mathrm{NH}_{2} \mathrm{OH} . \mathrm{HCl} 0,04 \text { mol L-1 em ácido } \\
\text { acético a } 25 \%\end{array}$ & 1,8 & C \\
\hline \multirow{3}{*}{ Orgânica } & $\begin{array}{l}\mathrm{H}_{2} \mathrm{O}_{2} 30 \%+\mathrm{HNO}_{3} 0,02 \mathrm{~mol} \mathrm{~L}^{-1} \mathrm{na} \\
\text { proporção de } 5: 3\end{array}$ & 2,0 & D1 \\
\hline & $\mathrm{H}_{2} \mathrm{O}_{2} 30 \%$ & 2,0 & D2 \\
\hline & $\mathrm{NH}_{4} \mathrm{OAc} 3,2 \mathrm{~mol} \mathrm{~L}^{-1}$ em HNO${ }_{3}$ a $20 \%$ & & D3 \\
\hline Residual & $\mathrm{HClO}_{4}+\mathrm{HNO}_{3}+\mathrm{HF} 48 \%(1: 1: 2)$ & & $\mathrm{E}$ \\
\hline
\end{tabular}

manual de instruções do aparelho. Para todos os elementos, as leituras só foram feitas quando a curva de calibração utilizada apresentava $r^{2} \geq 0,99$.

\section{TRATAMENTO ESTATÍSTICO}

A concentração total dos elementos em cada ponto e em cada período de coleta foi expressa como Média \pm DP (desvio-padrão) de triplicata. Como os resultados obtidos contêm um grande número de variáveis, as médias obtidas foram submetidas aos seguintes métodos exploratórios: análise de componentes principais (PCA) e análise hierárquica de agrupamentos (HCA), sendo estas técnicas estatísticas complementares que possuem grande aceitação na análise de dados químicos (Moita-Neto e Moita, 1998). O PCA foi utilizado para mostrar as principais correlaçōes de todos os metais analisados quimicamente e para colocar tanto os casos (pontos de coleta) quanto as variáveis (metais), em gráficos de duas dimensões, a partir de dois fatores. O HCA, por sua vez, agrupou os pontos de coleta por similaridade, através do método de Ward, sendo utilizada como medida a distância Euclidiana.

Para a comparação das concentrações totais médias dos elementos entre os períodos de seca e cheia foram aplicados testes-t para a média dos dez pontos, já que a intenção era apenas comparar os períodos sazonais, e não os pontos. Quanto às distribuições relativas em percentuais, foram comparadas ponto a ponto e em cada período de coleta por meio da aplicação de ANOVA de dupla entrada para cada fração.

\section{RESULTADOS E DISCUSSÃO}

\section{DIFRAÇÃO DE RAIOS X}

Quanto à constituição mineralógica dos sedimentos do Lago do Parú, a difração de raios X (Figura 3) mostrou grande quantidade de quartzo e uma marcada presença de montmorilonita, além de anortita, clinocloro e caulinita, 
sendo que os mesmos picos foram encontrados nos dois períodos de coleta.

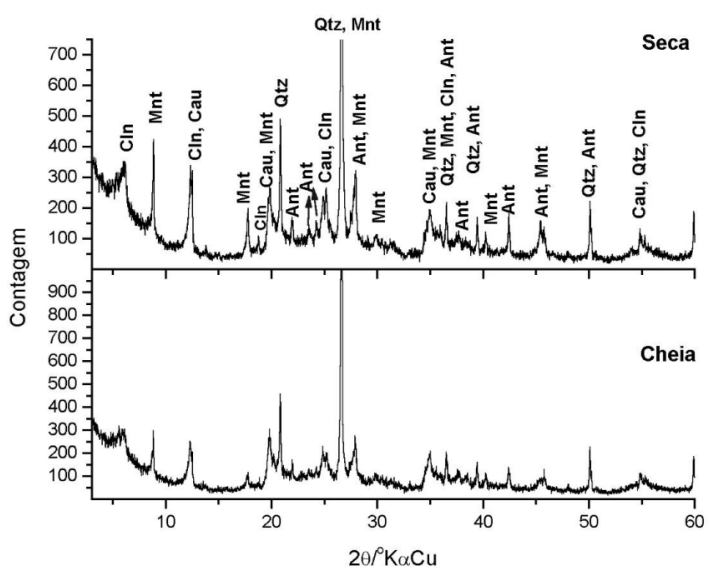

Figura 3 - Difração de raios X dos sedimentos do Lago do Parú na seca (2005) e na cheia (2006). CIn: clinocloro; Mnt: montmorilonita; Cau: caulinita; Qtz: quartzo; Ant: anortita.

$$
\begin{aligned}
& \text { Residual } \\
& \text { Orgânica } \\
& \text { Oxidica } \\
& \text { Carbonácea } \\
& \text { Trocável } \\
& \hline \text { Trat }
\end{aligned}
$$

Seca

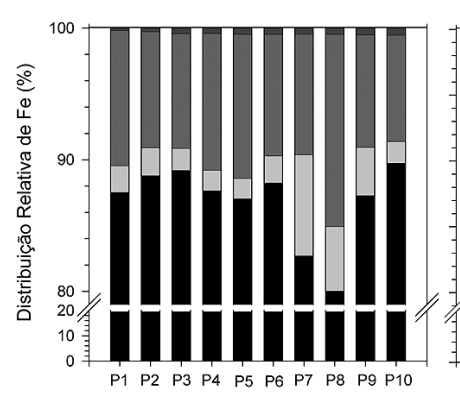

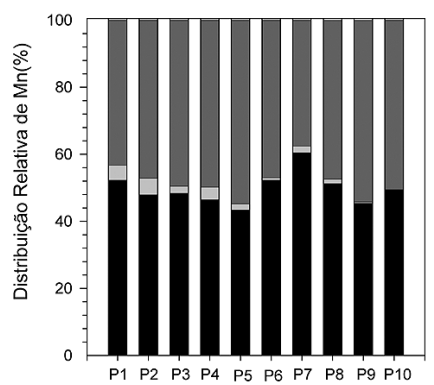

Pontos de Coleta

Figura 4 - Distribuições relativas de Fe e Mn entre as frações geoquímicas dos sedimentos do Lago do Parú coletados nos períodos de seca (2005) e cheia (2006).

\section{CONCENTRAÇÕES TOTAIS E DISTRIBUIÇÕES RELATIVAS}

$\mathrm{O} \mathrm{Fe}$ apresentou a maior concentração total média, provavelmente devido ao fato deste ser um dos elementos mais comuns na crosta terrestre (Sienko e Plane, 1977; Lindsay, 1979). Seus valores foram de $44.738 \pm 926 \mu \mathrm{g} \mathrm{g}^{-1}$ na seca $\mathrm{e}$ $43.016 \pm 625 \mu \mathrm{g} \mathrm{g}^{-1}$ na cheia, sendo a seca o período que apresentou maior concentração em um nível de significância de $99 \%(p=0,001)$. O Mn obteve concentração média bem menor que a do Fe, alcançando $176 \pm 30 \mu \mathrm{g} \mathrm{g}^{-1}$ na seca e 208 $\pm 40 \mu \mathrm{g} \mathrm{g}^{-1}$ na cheia, sendo menor na seca com um nível de significância de $90 \%(\mathrm{p}=0,058)$. A concentração total média de $\mathrm{Cu}$ não mostrou diferença entre os dois períodos sazonais estudados $(\mathrm{p}=0,9)$, sendo $85 \pm 13 \mu \mathrm{g} \mathrm{g}^{-1}$ na seca e $86 \pm 26$ $\mu \mathrm{g} \mathrm{g}^{-1}$ na cheia. As concentrações médias de $\mathrm{Zn}$ foram de 294 \pm 43 e $253 \pm 16 \mu \mathrm{g} \mathrm{g}^{-1}$ na seca e na cheia, respectivamente, sendo maior no período seco $(\mathrm{p}=0,01)$. A concentração média total de Co foi maior na cheia $\left(186 \pm 36 \mu \mathrm{g} \mathrm{g}^{-1}\right)$ que
Seca
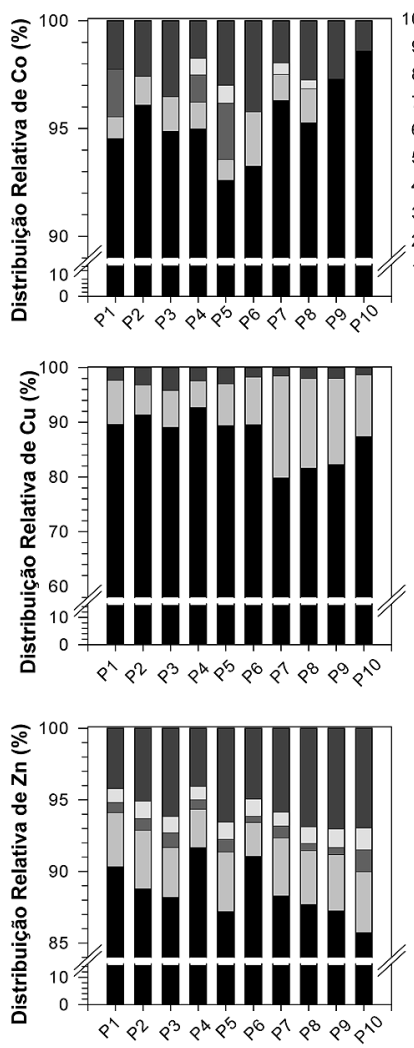

Cheia
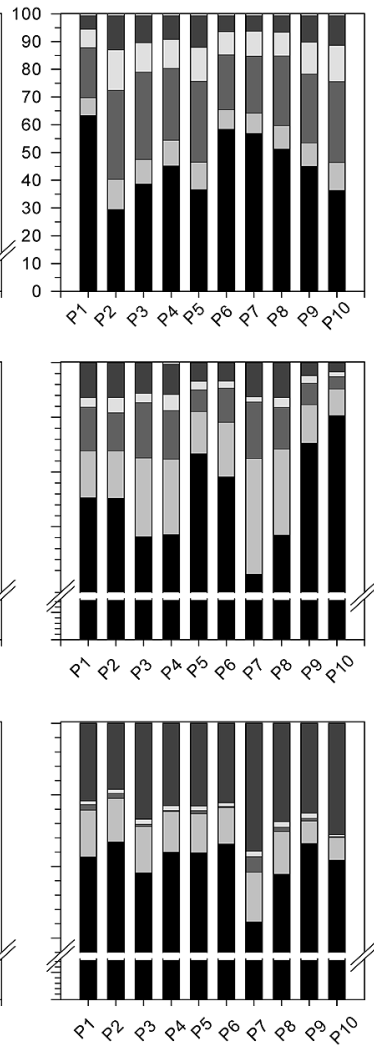

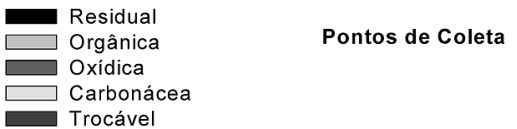

Figura 5 - Distribuições relativas de Co, Cu e Zn entre as frações geoquímicas dos sedimentos coletados em dez pontos do Lago do Parú nos períodos de seca (2005) e cheia (2006). 
na seca $\left(154 \pm 25 \mu \mathrm{g} \mathrm{g}^{-1}\right)$ em um nível de significância de 95 $\%(\mathrm{p}=0,03)$.

Todos os elementos, com exceção do Mn no período de cheia, mostraram-se associados principalmente à fração residual (Figuras 4 e 5), sugerindo que a maioria dos metais estudados está incorporada à matriz mineral, apresenta baixa mobilidade e origem natural, ou seja, não-antrópica (Audry et al., 2006). O Mn ainda chamou atenção por apresentar concentração decrescente no sentido $\mathrm{S}-\mathrm{N}$, do canal do rio (P1) para dentro do lago (P10) (Tabela 2).

Tabela 2 - Concentrações de elementos-traço encontradas nos sedimentos do lago do Parú nos períodos de seca (2005) e de cheia (2006). Todos os valores estão em $\mu \mathrm{g} \mathrm{g}^{-1}$, exceto pelas frações oxídica, orgânica e residual o Fe, que está $\mathrm{em} \mathrm{g} \mathrm{kg}^{-1}$.

\begin{tabular}{|c|c|c|c|c|c|c|c|c|c|c|c|}
\hline \multirow{2}{*}{ Elem } & \multirow[b]{2}{*}{$P C$} & \multicolumn{5}{|l|}{ Seca } & \multicolumn{5}{|l|}{ Cheia } \\
\hline & & Troc & Carb & $0 x$ & Org & Res & Troc & Carb & $0 x$ & Org & Res \\
\hline \multirow{10}{*}{$\mathrm{Fe}$} & P1 & $68 \pm 1,5$ & ND & $4,3 \pm 1,2$ & $0,8 \pm 0,1$ & $37 \pm 0,04$ & $243 \pm 22$ & $71 \pm 2,1$ & $3,5 \pm 0,1$ & $0,6 \pm 0,01$ & $39 \pm 0,03$ \\
\hline & P2 & $113 \pm 17$ & ND & $3,8 \pm 0,2$ & $0,9 \pm 0,2$ & $39 \pm 0,05$ & $316 \pm 3$ & $68 \pm 3,3$ & $4,7 \pm 0,1$ & $0,8 \pm 0,07$ & $34 \pm 0,02$ \\
\hline & P3 & $187 \pm 12$ & ND & $4,1 \pm 0,1$ & $0,8 \pm 0,1$ & $42 \pm 0,05$ & $334 \pm 9$ & $60 \pm 6,0$ & $6,2 \pm 0,2$ & $1,5 \pm 0,06$ & $33 \pm 0,03$ \\
\hline & P4 & $183 \pm 8$ & ND & $4,9 \pm 0,2$ & $0,7 \pm 0,1$ & $41 \pm 0,02$ & $265 \pm 9$ & $78 \pm 2,6$ & $4,9 \pm 0,1$ & $1,0 \pm 0,05$ & $39 \pm 0,03$ \\
\hline & P5 & $215 \pm 10$ & ND & $5,0 \pm 0,4$ & $0,7 \pm 0,1$ & $40 \pm 0,04$ & $347 \pm 20$ & $71 \pm 1,3$ & $6,5 \pm 0,2$ & $1,2 \pm 0,08$ & $34 \pm 0,03$ \\
\hline & P6 & $222 \pm 5$ & ND & $4,4 \pm 0,3$ & $1,0 \pm 0,1$ & $42 \pm 0,02$ & $396 \pm 4$ & $77 \pm 4,4$ & $6,2 \pm 0,1$ & $1,7 \pm 0,10$ & $40 \pm 0,03$ \\
\hline & P7 & $189 \pm 21$ & ND & $3,9 \pm 0,3$ & $3,3 \pm 0,6$ & $36 \pm 0,03$ & $390 \pm 8$ & $79 \pm 3,4$ & $4,7 \pm 1,3$ & $2,2 \pm 0,01$ & $40 \pm 0,04$ \\
\hline & P8 & $216 \pm 18$ & ND & $6,8 \pm 4,3$ & $2,3 \pm 0,4$ & $37 \pm 0,08$ & $407 \pm 8$ & $79 \pm 7,2$ & $5,8 \pm 0,1$ & $2,0 \pm 0,01$ & $40 \pm 0,03$ \\
\hline & P9 & $206 \pm 7$ & ND & $3,5 \pm 0,2$ & $1,5 \pm 0,7$ & $36 \pm 0,04$ & $402 \pm 9$ & $71 \pm 2,8$ & $6,0 \pm 0,3$ & $1,1 \pm 0,08$ & $32 \pm 0,02$ \\
\hline & P10 & $222 \pm 14$ & ND & $3,5 \pm 0,0$ & $0,7 \pm 0,1$ & $38 \pm 0,03$ & $314 \pm 13$ & $72 \pm 1,1$ & $4,9 \pm 0,4$ & $1,1 \pm 0,03$ & $27 \pm 0,05$ \\
\hline \multirow{10}{*}{ Mn } & P1 & $102 \pm 3$ & ND & ND & $10 \pm 1,5$ & $123 \pm 3$ & $120 \pm 7$ & $22 \pm 1,7$ & $58 \pm 1,5$ & $33 \pm 0,3$ & $23 \pm 3,7$ \\
\hline & P2 & $96 \pm 10$ & ND & ND & $10 \pm 1,0$ & $98 \pm 3$ & $126 \pm 1$ & $22 \pm 0,4$ & $59 \pm 0,6$ & $34 \pm 0,5$ & $10 \pm 3,3$ \\
\hline & P3 & $94 \pm 5$ & ND & ND & $4 \pm 0,3$ & $92 \pm 3$ & $98 \pm 1$ & $21 \pm 0,4$ & $56 \pm 2,1$ & $27 \pm 1,0$ & $44 \pm 8,1$ \\
\hline & P4 & $96 \pm 2$ & ND & ND & $7 \pm 0,1$ & $90 \pm 2$ & $123 \pm 1$ & $21 \pm 0,3$ & $56 \pm 1,2$ & $29 \pm 0,3$ & ND \\
\hline & P5 & $99 \pm 1$ & ND & ND & $3 \pm 0,3$ & $79 \pm 4$ & $98 \pm 2,5$ & $21 \pm 0,6$ & $54 \pm 1,6$ & $28 \pm 0,6$ & $8 \pm 5,6$ \\
\hline & P6 & $78 \pm 2$ & ND & ND & $1 \pm 0,5$ & $87 \pm 2$ & $111 \pm 1$ & $21 \pm 0,5$ & $54 \pm 0,9$ & $27 \pm 0,7$ & ND \\
\hline & P7 & $58 \pm 7$ & ND & ND & $3 \pm 0,9$ & $94 \pm 4$ & $102 \pm 1$ & $20 \pm 0,6$ & $55 \pm 0,6$ & $26 \pm 0,8$ & ND \\
\hline & P8 & $69 \pm 6$ & ND & ND & $2 \pm 1,1$ & $75 \pm 6$ & $103 \pm 5$ & $21 \pm 0,4$ & $55 \pm 0,3$ & $28 \pm 0,8$ & ND \\
\hline & P9 & $76 \pm 1$ & ND & ND & $0,5 \pm 0,2$ & $64 \pm 5$ & $88 \pm 2$ & $21 \pm 1,0$ & $55 \pm 0,9$ & $23 \pm 1,7$ & ND \\
\hline & P10 & $77 \pm 1$ & ND & ND & ND & $76 \pm 4$ & $75 \pm 1$ & $21 \pm 0,7$ & $55 \pm 0,5$ & $20 \pm 0,4$ & ND \\
\hline \multirow{10}{*}{ Co } & P1 & $3,6 \pm 0,92$ & ND & $3,55 \pm 2,33$ & $1,61 \pm 0,68$ & $152 \pm 5$ & $14,7 \pm 1,3$ & $17,7 \pm 3,7$ & $48,1 \pm 4,5$ & $17,2 \pm 2,2$ & $169 \pm 9$ \\
\hline & P2 & $4,36 \pm 1,19$ & ND & ND & $2,25 \pm 0,37$ & $158 \pm 5$ & $18,2 \pm 2,1$ & $20,6 \pm 2,3$ & $45,2 \pm 6,0$ & $15,3 \pm 3,0$ & $42 \pm 9$ \\
\hline & P3 & $4,28 \pm 0,86$ & ND & ND & $1,97 \pm 0,63$ & $111 \pm 5$ & $17,8 \pm 2,7$ & $18,2 \pm 1,5$ & $54,3 \pm 2,6$ & $15,3 \pm 0,5$ & $67 \pm 9$ \\
\hline & P4 & $2,54 \pm 0,20$ & $1,12 \pm 0,06$ & $1,85 \pm 0,07$ & $1,82 \pm 1,83$ & $139 \pm 2$ & $16,6 \pm 4,0$ & $18,8 \pm 0,9$ & $46,9 \pm 11,5$ & $16,7 \pm 0,8$ & $82 \pm 8$ \\
\hline & P5 & $4,95 \pm 0,36$ & $18,43 \pm 0,45$ & $4,35 \pm 3,89$ & $1,57 \pm 1,8$ & $154 \pm 6$ & $19,8 \pm 3,1$ & $20,1 \pm 1,1$ & $47,7 \pm 3,3$ & $16,2 \pm 1,7$ & $60 \pm 9$ \\
\hline & P6 & $4,69 \pm 2,65$ & ND & ND & $2,8 \pm 1,45$ & $102 \pm 6$ & $13,6 \pm 0,8$ & $17,9 \pm 1,1$ & $42,5 \pm 12,1$ & $15,0 \pm 3,6$ & $126 \pm 9$ \\
\hline & P7 & $2,75 \pm 1,41$ & $0,76 \pm 0,17$ & ND & $1,69 \pm 0,92$ & $136 \pm 6$ & $12,6 \pm 1,6$ & $18,2 \pm 1,7$ & $41,9 \pm 2,1$ & $14,8 \pm 0,5$ & $116 \pm 10$ \\
\hline & P8 & $4,33 \pm 1,07$ & $0,64 \pm 0,28$ & ND & $2,49 \pm 0,98$ & $151 \pm 6$ & $12,2 \pm 0,8$ & $15,7 \pm 0,7$ & $46,8 \pm 3,9$ & $15,7 \pm 0,8$ & $95 \pm 6$ \\
\hline & P9 & $4,72 \pm 2,55$ & ND & ND & ND & $168 \pm 5$ & $17,7 \pm 1,0$ & $20,1 \pm 0,2$ & $43,4 \pm 3,0$ & $14,8 \pm 1,2$ & $79 \pm 10$ \\
\hline & P10 & $2,75 \pm 1,30$ & ND & ND & ND & $192 \pm 3$ & $17,5 \pm 2,0$ & $20,0 \pm 2,7$ & $45 \pm 3,6$ & $15,4 \pm 2,4$ & $56 \pm 8$ \\
\hline \multirow{10}{*}{$\mathrm{Cu}$} & P1 & $1,7 \pm 0,4$ & ND & ND & $5,9 \pm 0,4$ & $66 \pm 5$ & $4,6 \pm 0,7$ & $1,2 \pm 0,2$ & $5,8 \pm 3,9$ & $6,2 \pm 0,2$ & $55 \pm 8$ \\
\hline & P2 & $3,1 \pm 1,1$ & ND & ND & $5,4 \pm 0,2$ & $91 \pm 6$ & $4,0 \pm 0,1$ & $1,8 \pm 0,4$ & $4,4 \pm 2,1$ & $5,4 \pm 1,0$ & $47 \pm 7$ \\
\hline & P3 & $3,3 \pm 1,1$ & ND & ND & $5,3 \pm 0,8$ & $70 \pm 5$ & $3,6 \pm 0,8$ & $1,0 \pm 0,7$ & $6,6 \pm 1,2$ & $9,3 \pm 0,3$ & $44 \pm 4$ \\
\hline & P4 & $2,0 \pm 0,4$ & ND & ND & $4,0 \pm 0,7$ & $76 \pm 3$ & $3,5 \pm 0,3$ & $1,7 \pm 0,3$ & $5,4 \pm 0,6$ & $8,3 \pm 0,8$ & $41 \pm 6$ \\
\hline & P5 & $2,2 \pm 0,5$ & ND & ND & $5,8 \pm 0,2$ & $67 \pm 7$ & $3,1 \pm 0,1$ & $1,5 \pm 0,8$ & $3,7 \pm 1,6$ & $7,2 \pm 0,4$ & $78 \pm 7$ \\
\hline & P6 & $3,1 \pm 1,1$ & ND & ND & $5,4 \pm 0,2$ & $89 \pm 6$ & $2,6 \pm 0,3$ & $1,0 \pm 0,2$ & $4,8 \pm 1,2$ & $7,63 \pm 0,3$ & $61 \pm 4$ \\
\hline & P7 & $1,4 \pm 0,9$ & ND & ND & $17,3 \pm 2,7$ & $74 \pm 5$ & $7,3 \pm 0,8$ & $1,0 \pm 0,4$ & $12,2 \pm 1,5$ & $25,0 \pm 1,5$ & $73 \pm 5$ \\
\hline & P8 & $1,9 \pm 0,4$ & ND & ND & $15,6 \pm 0,2$ & $78 \pm 6$ & $4,9 \pm 0,5$ & $1,4 \pm 1,2$ & $5,9 \pm 2,5$ & $12,1 \pm 0,5$ & $53 \pm 4$ \\
\hline & P9 & $1,1 \pm 0,3$ & ND & ND & $9,2 \pm 0,4$ & $48 \pm 6$ & $2,3 \pm 0,7$ & $1,4 \pm 0,7$ & $3,9 \pm 2,9$ & $7,0 \pm 1,6$ & $84 \pm 6$ \\
\hline & P10 & $1,2 \pm 0,5$ & ND & ND & $10,4 \pm 0,6$ & $80 \pm 7$ & $2,2 \pm 0,5$ & $1,2 \pm 0,7$ & $3,0 \pm 1,5$ & $6,5 \pm 0,2$ & $121 \pm 7$ \\
\hline
\end{tabular}




\begin{tabular}{|c|c|c|c|c|c|c|c|c|c|c|c|}
\hline & & Seca & & & & & Cheia & & & & \\
\hline Elem & PC & Troc & Carb & $0 x$ & Org & Res & Troc & Carb & $0 x$ & Org & Res \\
\hline \multirow{10}{*}{ Zn } & $\mathrm{P} 1$ & $12 \pm 0,2$ & $2,9 \pm 0,3$ & $2,1 \pm 0,3$ & $11 \pm 1$ & $268 \pm 4,0$ & $14,1 \pm 0,2$ & $0,64 \pm 0,46$ & $1,0 \pm 0,75$ & $8,5 \pm 0,2$ & $90 \pm 2,8$ \\
\hline & P2 & $18 \pm 1,5$ & $3,0 \pm 0,2$ & $2,6 \pm 0,8$ & $12 \pm 2,6$ & $240 \pm 2,5$ & $11,6 \pm 0,6$ & $0,69 \pm 0,72$ & $0,87 \pm 1,17$ & $7,7 \pm 0,4$ & $89 \pm 5,3$ \\
\hline & P3 & $17 \pm 0,7$ & $3,2 \pm 0,2$ & $2,9 \pm 1,2$ & $10 \pm 0,2$ & $246 \pm 6,1$ & $15,9 \pm 1,1$ & $0,83 \pm 0,51$ & $0,37 \pm 0,47$ & $7,7 \pm 0,2$ & $88 \pm 2,6$ \\
\hline & P4 & $14 \pm 0,2$ & $3,4 \pm 0,9$ & $2,5 \pm 0,5$ & $10 \pm 0,1$ & $337 \pm 8,7$ & $15,4 \pm 0,5$ & $0,92 \pm 0,50$ & $0,17 \pm 0,21$ & $7,6 \pm 0,3$ & $92 \pm 5,9$ \\
\hline & P5 & $17 \pm 0,1$ & ND & $2,4 \pm 0,3$ & $9 \pm 0,4$ & $234 \pm 4,1$ & $13,7 \pm 1,0$ & $0,73 \pm 0,64$ & $0,57 \pm 0,31$ & $6,5 \pm 0,7$ & $87 \pm 3,7$ \\
\hline & P6 & $18 \pm 0,4$ & $4,4 \pm 1,4$ & $1,7 \pm 0,4$ & $8 \pm 1,2$ & $335 \pm 6,6$ & $14,8 \pm 0,5$ & $0,67 \pm 0,45$ & $0,23 \pm 0,40$ & $6,8 \pm 0,4$ & $91 \pm 5,0$ \\
\hline & P7 & $18 \pm 1,4$ & $3,0 \pm 0,2$ & $2,6 \pm 0,7$ & $12 \pm 2,6$ & $274 \pm 6,0$ & $24,4 \pm 0,5$ & $1,03 \pm 0,02$ & $2,97 \pm 0,29$ & $9,5 \pm 0,7$ & $88 \pm 3,8$ \\
\hline & P8 & $19 \pm 1,0$ & $3,2 \pm 0,2$ & $1,4 \pm 0,3$ & $10 \pm 0,6$ & $243 \pm 5,8$ & $18,0 \pm 1,2$ & $0,99 \pm 0,42$ & $0,83 \pm 0,80$ & $7,8 \pm 0,5$ & $88 \pm 2,7$ \\
\hline & P9 & $18 \pm 0,2$ & $3,4 \pm 0,06$ & $1,4 \pm 0,8$ & $10 \pm 0,2$ & $232 \pm 4,5$ & $15,3 \pm 0,5$ & $0,85 \pm 0,06$ & $0,47 \pm 0,40$ & $3,8 \pm 0,4$ & $87 \pm 4,2$ \\
\hline & P10 & $16 \pm 1,8$ & $3,6 \pm 0,1$ & $3,6 \pm 2,4$ & $10 \pm 0,7$ & $203 \pm 6,1$ & $17,4 \pm 0,4$ & $0,32 \pm 0,42$ & $0,13 \pm 0,23$ & $3,6 \pm 0,3$ & $86 \pm 6,2$ \\
\hline
\end{tabular}

$\mathrm{PC}=$ Ponto de coleta; ND = Não detectado; Elem. = elemento, Troc. = fração trocável, Carb. = fração carbonácea, Ox. = fração oxídica, Org. = fração orgânica, Res. = fração residual

Quanto à distribuição relativa percentual (Figuras 4 e 5), a afinidade dos elementos pela fração trocável seguiu a seguinte ordem decrescente: Mn, Zn, Co, Cu e Fe. Porém, 0,41 \% de fração trocável de $\mathrm{Fe}$, na seca, representam, em valores absolutos, uma média de $182 \mu \mathrm{g} \mathrm{g}^{-1}$, enquanto os $48 \%$ de fração trocável média do $\mathrm{Mn}$ no mesmo período representam uma média de somente $85 \mathrm{\mu g} \mathrm{g}^{-1}$ nesta fração. Mesmo assim, o Mn é considerado o elemento mais móvel ou biodisponível dos cinco metais estudados por apresentar maior percentual na fração trocável. A fração ligada a carbonatos foi praticamente inexistente em todos os elementos estudados.

Em termos relativos (\%), o $\mathrm{Fe}$ apresentou maior fração residual na seca que na cheia $(\mathrm{p}<0,05)$. Na orgânica, não houve diferença entre os períodos $(\mathrm{p}=0,7)$. Na oxídica foi maior na cheia $(\mathrm{p}<0,05)$. A carbonácea só apareceu na cheia, por isso, não passou no teste de normalidade. A trocável também não passou pelo teste de normalidade, mas apresentou-se maior na cheia $(p=0,001)$. Não houve diferença entre os pontos em todas as fraçōes, exceto pela trocável $(\mathrm{p}=0,006)$. Este resultado revela que há uma certa movimentação do Fe ligado à rede cristalina e também um aumento da concentração de carbonatos no Lago do Parú devido à entrada da água do Rio Solimões. O processo de mistura de água preta dos igarapés que deságuam no lago, com a água branca do Solimões que entra pela boca do lago, causa uma alteração nas condições físicas e químicas no lago. Como as fraçôes geoquímicas são sensíveis a mudanças de $\mathrm{pH}$ e condutância (Syrovetnik, 2005), os elementos se associam e dissociam-se delas nos diferentes períodos sazonais.

Quanto ao $\mathrm{Mn}$, tanto a fração residual como a orgânica foram maiores na seca do que na cheia $(p=0,001)$. Na cheia, o Mn não foi detectado na fração residual na maioria dos pontos de coleta, indicando que passou por um processo de solubilização neste período. Tal comportamento indica que este metal permanece como constituinte do sedimento superficial do Lago do Parú por um curto período de tempo, sendo remobilizado na cheia. A parte do Mn ligada à matéria orgânica foi maior na cheia do que na seca $(\mathrm{p}=0,001)$. Ficaram ausentes na seca as frações oxídica e carbonácea ligadas ao Mn, porém apresentando médias de 26 e 9,8\% na cheia, respectivamente. Como as águas do Rio Solimōes contêm Mn (Esteves, 1998), alta quantidade de sólidos em suspensão e são carbonatadas (Furch et al, 1983), colaborando com a entrada de mais Mn no lago e em seus sedimentos, os processos de adsorção/dessorção, precipitação/dissolução se tornam mais efetivos (Manaham, 1999), causando uma alta mobilização deste metal no Lago do Parú. Para a fração trocável, não houve diferença entre os períodos sazonais. Em valores absolutos, as concentrações de $\mathrm{Mn}$ na fração trocável são da mesma ordem de grandeza do Fe na mesma fração, nas duas épocas de coleta. Como as frações carbonácea, orgânica e oxídica apresentaram aumento de concentração na cheia, a redução drástica de concentração na fração residual indica que o Mn liberado associa-se a essas fraçôes quando ressolubilizado. Para nenhuma fração houve diferença entre os pontos $(p>0,05)$.

A fração do $\mathrm{Cu}$ na forma residual foi maior na seca do que na cheia $(\mathrm{p}<0,05)$. Na fração do Cu ligado à matéria orgânica, não houve diferença entre períodos ( $p>0,05)$, como o elemento $\mathrm{Fe}$. Tal similaridade entre os períodos se deve provavelmente à grande afinidade que o $\mathrm{Cu}$ possui por esta fração. As fraçōes oxídica, carbonácea e trocável foram maiores na cheia do que na seca (com $p=0,001, p=0,001$ e $p=0,002$, respectivamente). Provavelmente a fração carbonácea foi maior na cheia devido à entrada da água rica em carbonatos do Rio Solimões no lago, e fração oxídica devido à redução provocada pela falta de oxigênio no hipolímnio. Novamente, em nenhuma das frações houve diferença entre os pontos ( $p>0,05)$.

$\mathrm{O}$ Co apresentou distribuição relativa semelhante à do $\mathrm{Cu}$, sendo a fração residual maior na seca $(\mathrm{p}=0,001)$, e as frações orgânica, oxídica, carbonácea e trocável maiores na cheia do que na seca $(\mathrm{p}=0,001)$, não apresentando também nenhuma das fraçōes diferenças entre os pontos de coleta $(p>0,05)$. $\mathrm{Na}$ cheia, o aumento da concentração de Co em todas as frações geoquímicas exceto na residual, fração em que diminuiu, sugere que este elemento foi liberado desta para as outras frações neste período. 
Quanto ao Zn, este apresentou fração residual maior na cheia do que na seca $(p=0,04)$, e fraçôes orgânica, oxídica e carbonácea maiores na seca, com $\mathrm{p}=0,01, \mathrm{p}=0,007$ e $\mathrm{p}=0,001$, respectivamente. A fração trocável não apresentou diferença entre os períodos $(p>0,05)$. Como para a maioria dos elementos, em nenhuma das fraçōes houve diferença entre os pontos de coleta $(\mathrm{p}>0,05)$.

Sendo assim, a fração ligada a óxidos de ferro e manganês foi maior nos elementos Co e $\mathrm{Mn}$, somente no período de cheia, com uma média de $26 \%$ para ambos, o que representa,

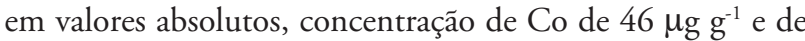
$\mathrm{Mn}$ de $56 \mu \mathrm{g} \mathrm{g}^{-1}$. O Fe alcançou médias de $10 \%$ na seca e $13 \%$ na cheia, sendo que, em termos absolutos, estes valores representam 4.434 e $5.356 \mu \mathrm{g} \mathrm{g}^{-1}$, respectivamente.

A fração ligada à matéria orgânica dos sedimentos do Lago do Parú foi percentualmente maior representada pelo elemento Mn no período de cheia, com 12,7\%, seguida pelo $\mathrm{Cu}$ com $11,2 \%$ e do Co, com $9 \%$ no mesmo período. O Fe, com percentual médio próximo $3 \%$ nos dois períodos sazonais, apresentou boa ligação com esta fração, obtendo em termos absolutos concentraçóes de 1.281 e $1.339 \mu \mathrm{g} \mathrm{g}^{-1}$ na seca e na cheia, respectivamente.

Quanto à fração residual, esta foi predominante em grande parte dos elementos estudados, sendo que todos os elementos apresentaram variação nesta fração. As menores frações residuais foram do $\mathrm{Mn}$, na cheia, com média de 3,5 \% (e até mesmo ausente em alguns pontos de coleta), do Co, também na cheia, com uma média percentual de $46 \%$, seguido do Mn na seca, com uma média de $50 \%$. Para o restante dos elementos, a fração residual ficou com uma média mínima de $76 \%$ (Cu na cheia) e média máxima de $94 \%$ (Co na seca).

\section{ANÁLISES MULTIVARIADAS}

Neste trabalho foram utilizadas análises exploratórias multivariadas (PCA e HCA) para: 1) verificar as correlaçōes entre todas as variáveis, encontrando conjuntos das mesmas que possam ser consideradas redundantes e 2) descrever a similaridade entre as amostras, considerando o conjunto total de variáveis (Bini, 2004), além de reduzir a quantidade de variáveis utilizando critérios objetivos para a construção de gráficos bidimensionais contendo maior informação estatística (Moita-Neto e Moita, 1998).

As n-variáveis originais foram organizadas em ordem decrescente de máxima variância, ou seja, a componente principal 1 (PC1) detém mais informação estatística que a componente principal 2 (PC2), que por sua vez tem mais informação estatística que a componente principal 3 (PC3) e assim por diante. Este método permitiu a redução da dimensionalidade dos pontos representativos das amostras.

Os autovalores significativos para as concentrações de metais no total e nas diferentes frações geoquímicas foram utilizados como critério de redução, e a representatividade dos PC1 e PC2 somados em relação aos resultados obtidos referentes às concentraçôes médias totais e fracionadas dos elementos analisados (Tabela 3). A soma dos PC1 e PC2 na forma percentual diz o quanto dos dados, de cada fração, foi utilizado para a análise estatística PCA. A maior representatividade ocorreu na fração orgânica durante a cheia.

As correlações de Pearson com valor absoluto de $\left|\mathrm{r}^{2}>0,5\right|$ entre os metais estudados no período de seca mostram que a única correlação positiva foi $\mathrm{Fe}-\mathrm{Zn}$, enquanto as negativas foram Co-Zn e Co-Fe. Na fração trocável, a correlação FeZn se manteve, e a correlação negativa foi Fe-Mn. A fração carbonácea não apresentou correlação, provavelmente devido ao fato da baixíssima concentração de metais a ela ligados. $\mathrm{Na}$ fração oxídica foi observada apenas uma correlação significativa, que ocorreu para $\mathrm{Cu}-\mathrm{Co}$. $\mathrm{Na}$ fração orgânica dos sedimentos, as correlaçōes positivas foram observadas para $\mathrm{Fe}-\mathrm{Cu}, \mathrm{Fe}-\mathrm{Zn}$ e $\mathrm{Cu}-\mathrm{Zn}$ e a única correlação negativa foi $\mathrm{Cu}-\mathrm{Mn}$. $\mathrm{Na}$ fração residual, foram encontradas somente correlaçôes negativas para Co-Zn e Co-Fe.

$\mathrm{Na}$ cheia foi observado um número maior de correlações fortes que na seca (Tabela 4): i) a fração total apresentou ${ }^{2}$ positivo para $\mathrm{Fe}-\mathrm{Zn}$, Fe-Co e Co-Zn, e negativo para $\mathrm{Mn}-\mathrm{Cu}$; ii) a fração trocável obteve $\mathrm{r}^{2}$ positivo para $\mathrm{Cu}-\mathrm{Zn}$ e negativo para Co-Zn e Co-Cu; iii) a fração carbonácea apresentou $\mathrm{r}^{2}$ negativo para as correlaçōes $\mathrm{Mn}-\mathrm{Fe}$ e $\mathrm{Mn}-\mathrm{Zn}$; iv) a fração oxídica obteve $\mathrm{r}^{2}$ positivo para $\mathrm{Cu}-\mathrm{Zn}$ e negativo para Fe-Mn; v) a fração orgânica teve $\mathrm{r}^{2}$ positivo para as correlaçōes $\mathrm{Cu}$ $\mathrm{Fe}, \mathrm{Cu}-\mathrm{Zn}, \mathrm{Mn}-\mathrm{Zn}, \mathrm{Mn}-\mathrm{Co}$, e negativo para Fe-Co; e vi) a fração residual oteve $r^{2}$ positivo para Fe-Zn, Fe-Co e Co-Zn

Tabela 3 - Autovalores significativos e percentuais de PC1 e PC2 obtidos para as médias das concentrações dos metais analisados nas frações geoquímicas.

\begin{tabular}{|c|c|c|c|c|c|}
\hline \multirow{2}{*}{ Fração } & \multirow{2}{*}{ Período } & \multicolumn{3}{|c|}{ Autovalor } & \multirow{2}{*}{ PC1 + PC2 (\%) } \\
\hline & & 1 & 2 & 3 & \\
\hline \multirow{2}{*}{ Total } & Seca & 2,458 & 1,134 & 0,772 & 71,84 \\
\hline & Cheia & 2,955 & 1,212 & 0,587 & 83,34 \\
\hline \multirow{2}{*}{ Trocável } & Seca & 2,514 & 1,411 & 0,668 & 78,50 \\
\hline & Cheia & 2,412 & 1,571 & 0,626 & 79,67 \\
\hline \multirow{2}{*}{ Carbonácea } & Seca & 1,226 & 1,015 & 0,759 & 74,71 \\
\hline & Cheia & 2,374 & 1,189 & 0,747 & 71,28 \\
\hline \multirow{2}{*}{ Oxídica } & Seca & 1,725 & 1,232 & 0,666 & 73,93 \\
\hline & Cheia & 2,295 & 1,609 & 0,783 & 78,08 \\
\hline \multirow{2}{*}{ Orgânica } & Seca & 2,470 & 1,664 & 0,798 & 82,68 \\
\hline & Cheia & 2,355 & 1,989 & 0,426 & 86,88 \\
\hline \multirow{2}{*}{ Residual } & Seca & 2,488 & 1,016 & 0,848 & 70,09 \\
\hline & Cheia & 2,797 & 1,248 & 0,672 & 80,91 \\
\hline
\end{tabular}


e negativo para $\mathrm{Cu}-\mathrm{Zn}$ e Co-Fe. $\mathrm{O}$ aumento de correlaçōes na cheia representa muito bem o papel do Rio Solimões no fornecimento e movimentação de nutrientes para o Lago do Parú. Além disso, a entrada das águas do Rio Solimōes representa, para o Lago do Parú, mudanças das condiçôes físicas e químicas de seu sistema aquático, uma vez que este rio transporta cerca de $60 \%$ dos sedimentos carreados pela bacia do Rio Amazonas (Syler \& Boaventura, 2001). Assim, os valores de $\mathrm{pH}$ reduziram de 7,9 $\pm 0,7$ para $6,4 \pm 0,1$, enquanto a condutividade elétrica aumentou de $54 \pm 1,4$ para $65 \pm 3,4 \mu \mathrm{S} \mathrm{cm}^{-1}$ da seca para cheia. Essas mudanças alteram a suspensão/sedimentação dos metais, que dependem das partículas contendo argilominerais e matéria orgânica responsáveis pelos processos de floculação, precipitação ou dissolução (Siqueira et al., 2006).

Os gráficos do $\mathrm{PC} 1$ versus $\mathrm{PC} 2$, obtidos da fração total, caracterizam uma mudança na distribuição dos pontos de coletas (Figura 6) da seca para a cheia. O único ponto de coleta que se manteve no mesmo quadrante foi o $\mathrm{P} 9$. Os pontos $\mathrm{P} 6$, P7 e P8, apesar de mudarem de quadrante entre um período e outro, se mantiveram juntos. $\mathrm{O}$ mesmo foi observado
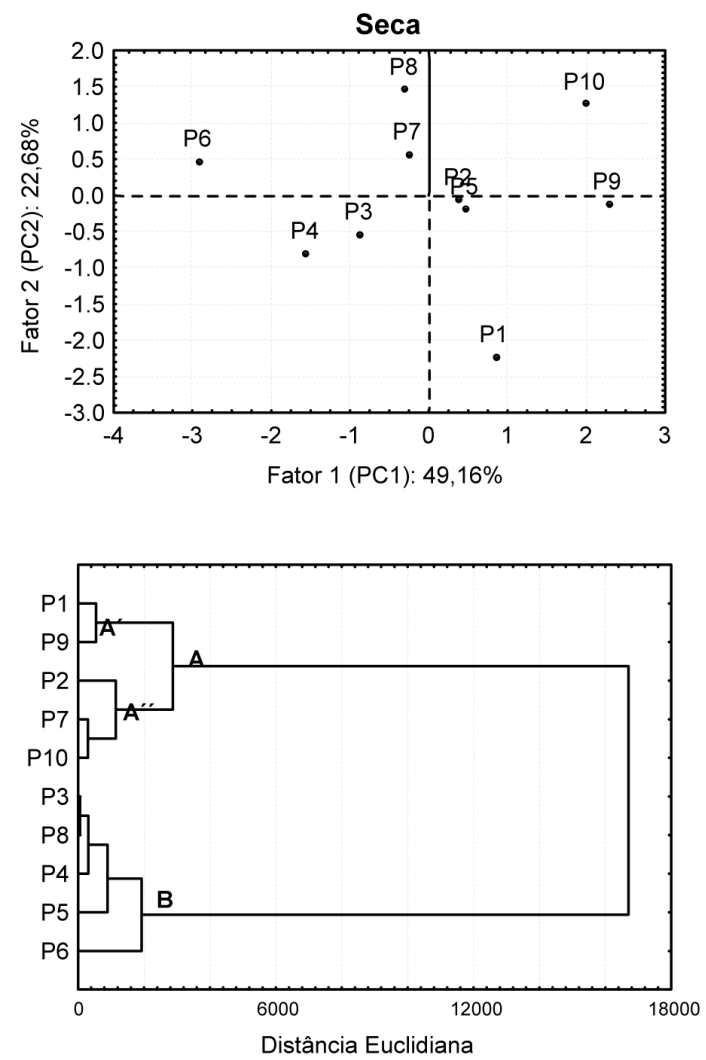

nos dois dendrogramas referentes, que são caracterizados pela formação de dois grupos diferentes entre si (Figura 6). Ambos dendrogramas apresentaram grande escala de distância Euclidiana, devido ao fato do Fe apresentar uma grande concentração em relação aos outros elementos. $\mathrm{Na}$ seca, o Grupo A foi formado por P1, P2, P7, P9 e P10 e o Grupo B por P3, P4, P5, P6 e P8. Particularmente, no Grupo A, observam-se dois subgrupos: A' e A" na distância Euclidiana

Tabela 4 - Correlações $\left(r^{2}>|0,500|\right)$ entre as concentrações dos metais estudados, encontradas nos sedimentos do Lago do Parú no período de seca (2005)

\begin{tabular}{llll}
\hline $\begin{array}{l}\text { Fração } \\
\text { Geoquímica }\end{array}$ & Metal & Positiva & Negativa \\
\hline \multirow{2}{*}{ Total } & Fe & Zn $(0,531)$ & Co $(0,656)$ \\
& Co & & Zn $(0,730)$ \\
\hline Trocável & Fe & Zn $(0,876)$ & Mn $(0,542)$ \\
\hline Oxídica & $\mathrm{Co}$ & $\mathrm{Cu}(0,501)$ & \\
\hline Orgânica & $\mathrm{Cu}$ & $\mathrm{Fe}(0,897), \mathrm{Zn}(0,505)$ & $\mathrm{Mn}(0,513)$ \\
& $\mathrm{Fe}$ & $\mathrm{Zn}(0,682)$ & \\
\hline Residual & $\mathrm{Co}$ & & $\mathrm{Zn}(0,695), \mathrm{Fe}(0,569)$ \\
\hline
\end{tabular}
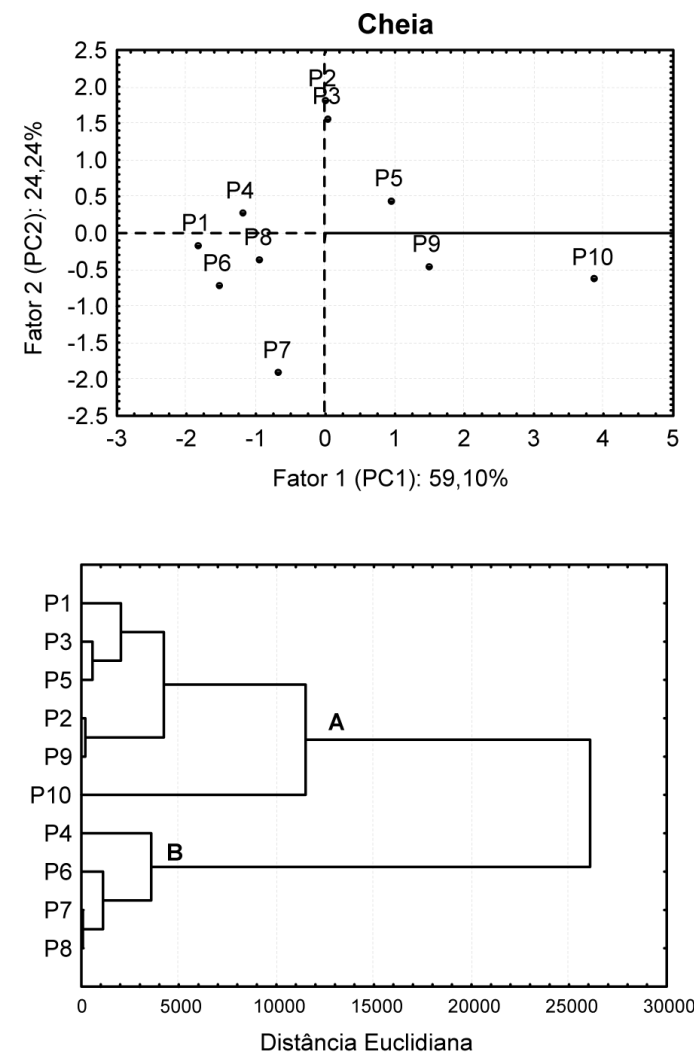

Figura 6 - PC e dendrogramas da concentração dos metais analisados na fração total dos sedimentos do Lago do Parú, nos períodos de seca (2005) e cheia (2006). 
Tabela 5 - Correlações $(>|0,500|)$ entre as concentrações dos elementos estudados, encontradas nos sedimentos do Lago do Parú no período de cheia (2006).

\begin{tabular}{|c|c|c|c|}
\hline $\begin{array}{l}\text { Fração } \\
\text { Geoquímica }\end{array}$ & Metal & Positiva & Negativa \\
\hline \multirow{3}{*}{ Total } & $\mathrm{Fe}$ & Zn $(0,892)$ & \\
\hline & Co & Zn $(0,549), \mathrm{Fe}(0,511)$ & \\
\hline & $\mathrm{Mn}$ & & $\mathrm{Cu}(0,833)$ \\
\hline \multirow{2}{*}{ Trocável } & $\mathrm{Cu}$ & $\operatorname{Zn}(0,664)$ & \\
\hline & Co & & $\operatorname{Zn}(0,603), \mathrm{Cu}(0,602)$ \\
\hline Carbonácea & $\mathrm{Mn}$ & & $\mathrm{Fe}(0,573), \mathrm{Zn}(0,525)$ \\
\hline \multirow{2}{*}{ Oxídica } & $\mathrm{Cu}$ & Zn $(0,879)$ & \\
\hline & $\mathrm{Fe}$ & & $\operatorname{Mn}(0,687)$ \\
\hline \multirow{3}{*}{ Orgânica } & $\mathrm{Cu}$ & $\mathrm{Fe}(0,760), \mathrm{Zn}(0,527)$ & \\
\hline & $\mathrm{Fe}$ & & Co $(0,546)$ \\
\hline & $\mathrm{Mn}$ & Zn $(0,711)$, Co $(0,533)$ & \\
\hline \multirow{2}{*}{ Residual } & $\mathrm{Fe}$ & Zn $(0,734)$, Co $(0,682)$ & Cu $(0,648)$ \\
\hline & $\mathrm{Zn}$ & Co $(0,526)$ & $\mathrm{Cu}(0,714)$ \\
\hline
\end{tabular}

abaixo de 3200. O Subgrupo A' é formado pelos pontos de coleta P1 e P9 e o A" apenas por P2, P7 e P10. Na cheia, o Grupo A é composto pelos pontos de coleta P1, P2, P3, P5 e P9, podendo ser dividido em dois subgrupos (A' e A"), cuja distância Euclidiana é maior que 11.000. O subgrupo A' é formado por P1, P2, P3, P5 e P9, ao passo que A" por P10. E o Grupo B é formado pelos pontos de coleta P4, P6, P7 e P8, podendo ser dividido também em dois subgrupos: B' composto somente por P4, e B", composto por P6, P7 e P8. Os dendrogramas mostram que os pontos de coleta $\mathrm{P} 1, \mathrm{P} 2$ e P10 se mantiveram no Grupo A durante os dois períodos amostrados. O mesmo pode ser dito para grupo B com os pontos de coleta P4, P6 e P8.

Os grupos formados revelam que a grande quantidade de partículas sólidas transportada pelo Rio Solimóes para dentro do Lago do Parú é acompanhada de diferentes processos de deposição. Entretanto, P4, P5 e P6 estão agrupados em mesmos grupos tanto na seca quanto na cheia, indicando que no meio do lago a deposição é mais homogênea que nas extremidades, formadas pelos pontos de coleta P1, P2, P3, P8, P9 e P10, respectivamente. Nas extremidades o agrupamento depende da época de coleta, ou seja, da altura da coluna d'água no Lago do Parú.

\section{CONCLUSÕES}

As concentrações totais de $\mathrm{Cu}$ e $\mathrm{Mn}$ na fração total não sofreram variações nos dois períodos amostrados, ao contrário de $\mathrm{Fe}, \mathrm{Zn}$ e Co, cujas concentraçōes no Lago do Parú dependem do processo de inundação do Rio Solimões. As análises multivariadas mostraram que os cinco metais estudados apresentaram diferentes associações nas fraçōes geoquímicas conforme o período sazonal amostrado, sendo que o carbonato dissolvido nas águas do Rio Solimões exerce papel importante no processo de formação dos sedimentos do Lago do Parú. Tais análises também apresentaram mudanças nas correlaçôes existentes entre os metais estudados, sendo em alguns casos, altas e, em outros, baixas ou inexistentes. Há mudanças de similaridades entres os pontos de coleta de acordo com o período amostrado, sugerindo que composição do sedimento superficial ao longo do Lago do Parú seja heterogênea.

\section{AGRADECIMENTOS}

Agradecemos à FAPEAM, pelo apoio ao projeto de pesquisa e ao CNPq, pela bolsa de estudos concedida ao longo do curso de mestrado da primeira autora. Agradecemos também à colaboração de todos que nos emprestaram equipamentos ou forneceram estrutura para a realização deste estudo, como o CPCRH/INPA e os professores do Departamento de Geologia da UFAM, Dr. Cláudio A. Milliotti e $\operatorname{Dr}^{\mathrm{a}}$ Adriana M. C. Horbe, Dra Marle A. Villacorta Correa, do Departamento de Pesca da UFAM, além do SIGLAG/INPA, pelas imagens de satélite do Lago do Parú.

\section{BIBLIOGRAFIA CITADA}

Audry, S.; Blanc, G.; Schäfer, J. 2006. Solid state partitioning of trace metals in suspended particulate matter from a river system affected by smelting-waste drainage. Science of the Total Environment, 363: 216-236.

Bacon, J.R.; Davidson, C.M. 2008. Is there a future for sequential chemical extraction? Analyst, 133: 25-46.

Behling, H.; Keim, G.; Irion, G.; Junk, W.; Mello, J.N. 2001. Holocene environmental changes in the Central Amazon Basin inferred from Lago Calado (Brazil). Palaeogeography, Palaeoclimatology, Palaeoecology, 173: 87-101.

Bini, L.M. 2004. Análises Multivariadas e Limnologia: Exploração, síntese e inferência de um mundo aquático complexo. In: Bicudo, C.E.M.; Bicudo, D.C. (Eds). Amostragem em Limnologia. Rima, São Carlos. p.73-107.

Borgnino, L.; Avena, M. De Pauli, C. 2006. Surface properties of sediments from two Argentinean reservoirs and the rate of phosphate release. Water Research ., 40: 2659-2666.

Esteves, F.A. 1998. Sedimentos límnicos. In: Esteves, F.A. Fundamentos de Limnologia. 2 ed. Rio de Janeiro: Interciência. p. 300-315.

Furch, K. Junk, W. J.; Dieterich, J.; Kochert, N. 1983. Seasonal variation in the major cation $(\mathrm{Na}, \mathrm{K}, \mathrm{Mg}$ and $\mathrm{Ca}$ ) content of the water of Lago Camaleão, an Amazonian floodplain-lake near Manaus, Brazil. Amazoniana. VIII (1): 75-89.

Ghrefat, h.; Yusuf, N. 2006. Assessing Mn, Fe, Cu, Zn, and Cd pollution in bottom sediments of Wadi Al-Arab Dam, Jordan. Chemosphere, 65: 2114-2121.

Hlavay, J.; Prohaska, T.; Weisz, M.; Wenzel, W.W.; Stingeder, G.J. 2004. Determination of trace elements bound to soils and 
sediment fractions. (IUPAC Technical Report). Pure and Applied Chemistry, 76 (2): 415-442.

Instituto Brasileiro de Geografia e Estatística (IBGE), 2007. [on line].(www.ibge.gov.br)

Ikem, A.; Egiebor, N.O.; Nyavor, K. 2003. Trace elements in water, fish and sediment from Tuskegee Lake, Southeastern USA. Water, Air, and Soil Pollution, 149: 51-75.

Kahn, A.; Soltanpour, P.N. 1978. Effect of wetting and drying on DTPA-extractable Fe, $\mathrm{Zn}, \mathrm{Mn}$ and $\mathrm{Cu}$ in soils. Communication in Soil Science and Plant Analysis, 9: 193-202.

Manaham, S. E. 1999. Environmental Chemistry. 7 ed. Boca Raton: Lewis Publishers.

McLaren, R.G.; Kanjanapa, K.; Navasumrit, P.; Gooneratne, S.R.; Ruchirawat, M. 2003. Cadmium in the water and sediments of the Chao Phraya River and associated waterways, Bangkok, Thailand. Water, Air, and Soil Pollution, 00: 1-14.

Moita-Neto, J.M.; Moita, G.C. 1998. Uma introdução à análise exploratória de dados multivariados. Química Nova, 21 (4): 467-469.

Nascimento, F.; Fenzl, N. 1997. Geoquímica de metais pesados em sedimentos do Rio Guamá e dos principais canais de drenagem de Belém, Pará, Brasil. Acta Amazônica, 27(4): 257-268.

Pestana, M.H.D.; Formoso, M.L.L. 2003. Temporal evaluation of $\mathrm{Cu}, \mathrm{Mn}, \mathrm{Pb}$ and $\mathrm{Zn}$ potential mobilities in stream sediments of a copper mining area in South Brazil. Journal de Physique IV France, 107: 1049-1052.

RADAMBRASIL. Programa de Integração Nacional. Levantamento de recursos Naturais. Vol. 18. Rio de Janeiro. 1978. 626 pp.
Lindsay, W. L. 1979. Chemical equilibrium in soils. New York: John-Wiley \& Sons. 449 pp.

Seyler, P.T.; Boaventura, G. R. 2001. Trace elements in the mainstream Amazon river. In: McClain, M.E.; Victoria, F.R.L.; Richey, J.E. (Eds). The biogeochemistry of the Amazon basin. Oxford Press, p. 307 - 327.

Sienko, M.J.; Plane, R.A. 1977. Elementos de transição II. In: Sienko, M.J.; Plane, R.A. (Eds.) Química. 5 ed. São Paulo: Nacional, cap.21, p. 436-454.

Siqueira, G. W., Pereira, S. F. P., Aprille, F. M. 2006. Determinação dos elementos-traço (Zn, Co e Ni) em sedimentos da Plataforma Continental Amazônica sob influência da descarga do Rio Amazonas. Acta Amazonica, 36(3): 321-326.

Syrovetnik, K. 2005. Long-term metal retention processes in a peat bog: field studies, data and modelling. Tese de Doutorado. Royal Institute of Technology. Stockholm, Sweden.

Tessier, A.; Campbell, P.G.C.; Bisson, M. 1979. Sequential extraction procedure for the speciation of particulate trace metals. Analytical Chemistry, 51: 844-850.

Tundisi, J.G.; Forsberg, B.R.; Devol, A.H.; Zaret, T.M.; Tundisi, T.M.; Santos, A.; Ribeiro, J.S.; Hardy, E. 1984. Mixing patterns in Amazon lakes. Hidrobiologia, 108 (1): 3-15.

Ure, A.M. 1991. Trace element speciation in soils, soil extracts and solutions. Mikrochimica Acta, II: 49-57.

Recebido em 07/03/2008

Aceito em 09/05/2008 
